\title{
Retrospective Analysis of Leishmaniasis in Central Tunisia: An Update on Emerging Epidemiological Trends
}

\author{
Akila Fathallah Mili1,3, Fatma Saghrouni1 ${ }^{1}$, Zeineb BenSaid ${ }^{2}$, \\ Yusr Saadi- BenAoun ${ }^{3}$, Ikram Guizani ${ }^{3}$ and Moncef BenSaid ${ }^{1}$ \\ ${ }^{1}$ Laboratory of Parasitology, Farhat Hached Hospital, Sousse \\ ${ }^{2}$ Service of Dermatology, Farhat Hached Hospital, Sousse \\ ${ }^{3}$ Laboratory of Parasitic Epidemiology and Ecology (LEEP) - LR00SP04, \\ Institut Pasteur, Tunis \\ Tunisia
}

\section{Introduction}

This study aimed at describing the spatio-temporal distribution of leishmaniasis in patients who have sought diagnosis in the laboratory of Parasitology of Farhat Hached hospital, Sousse, Tunisia, across the 1986-2010 period in order to: i) highlight important features and trends of leishmaniasis and its epidemiology; ii) and to assess whether the activity of the unit reflects the situation of the disease at the national level and whether it could constitute an indicator of public health relevance.

\section{Current situation of leishmaniasis in Tunisia}

Tunisia is located in Northern Africa, bordering the Mediterranean sea between Algeria and Libya. Its climate is of the hot temperate Mediterranean type. Bioclimatic zones range from humid in the north to saharian in the extreme south (Figure 1).

The country is divided into 24 governorates, each composed of a variable number of "delegations"; and each delegation is subdivided into localities also named "imadas" (Figure 2). Four forms of leishmaniasis are known to occur in Tunisia: i) the sporadic cutaneous leishmaniasis (SCL); ii) the chronic cutaneous leishmaniasis (CCL); iii) the zoonotic cutaneous leishmaniasis (ZCL); iv) the visceral leishmaniasis (VL).

\subsection{The sporadic cutaneous leishmaniasis (SCL)}

This form is caused by dermotropic zymodemes of Leishmania infantum, mainly the zymodeme MON 24 and to a lesser extent MON 1 (Aoun et al., 2000, 2008; Ben Ismail et al, 1986, 1992; Gramiccia et al., 1991; Haouas et al., 2007; Kallel et al., 2005, 2008b). The dog is supposed to be the reservoir as it is the case for the viscerotropic zymodemes and Phlebotomus perfiliewi as the phletotomine vector. But other vectors can not be excluded; following an outbreak of SCL in the locality of Oued Souani, le Kef governorate, P. langeroni was found infected by L. infantum (Guerbouj et al., 2007). 


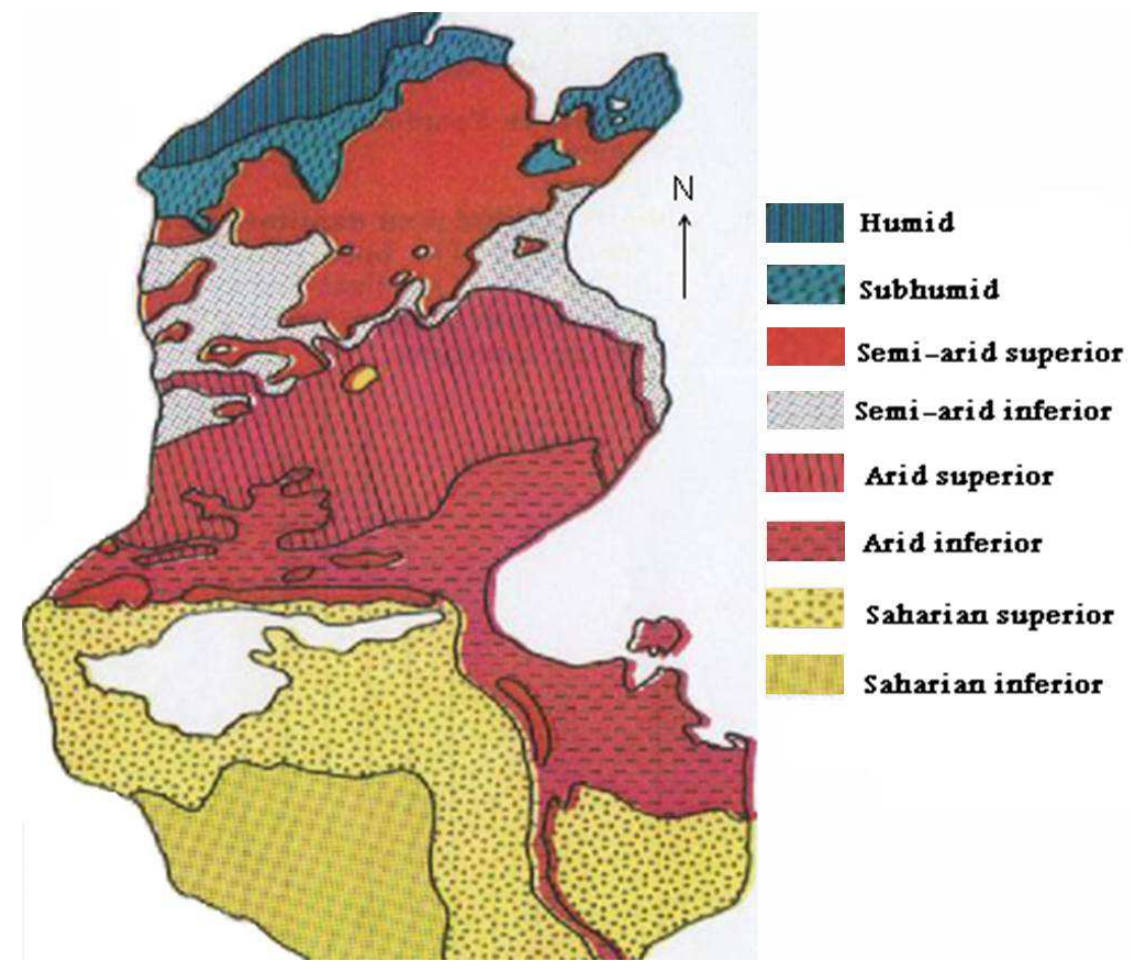

Fig. 1. Map of Tunisia showing the distribution of bioclimatic zones.

SCL was first described in 1917 in a patient from Sakiet Sidi Youssef (Le Kef governorate) located next to the Algerian frontier (Nicolle \& Blanc, 1917), and again in 1945 (Chadli et al., 1968; Vermeil, 1956). Since 1945, the disease has sporadically been reported with, however, an incidence that gradually increased from a median of one case /year between 1945 and 1955 to 22 cases /year in the 1990s and 59 cases/year in the 2000s (Table 1; Anonymous; Ben Abda et al., 2009; Ben Said et al., 2006; Ben Ismail \& Ben Rachid, 1989; Ben Rachid et al., 1983, 1992; Chadli et al., 1968 ; Chaffai et al., 1988; Ladjimi \& Lakhoua, 1955 ; Vermeil, 1956). SCL has long been supposed to be confined to the humid and subhumid bioclimatic areas north to the "dorsale" or "tunisian Ridge" (the eastern extension of the Atlas mountains), in rural areas where its distribution overlaps with that of VL (Ben Ismail et al., 1989; Ben Rachid et al., 1983; Ben Rachid \& Ben Ismail, 1989; Chadli et al., 1986 ; Vermeil, 1956). However, over the last three decades, many cases originating from central Tunisia governorates (Monastir, Sousse, Mahdia and Kairouan) and referred to our laboratory were found to be very suggestive of SCL on the basis of epidemiological, clinical and parasitological criteria. Typed strains obtained from some of these patients proved indeed to be L. infantum (Ben Said et al., 2006). These data were very indicative of SCL spread towards the south of the country. These findings were further confirmed by additional reports (Aoun et al, 2000, 2008; Ben Abda et al., 2009; Kallel et al., 2008a, 2008b). The revised SCL distribution is shown in figure 3. SCL usually occurs sporadically within no particular season. However, over the last few years, local outbreaks were reported like that of Sidi Bourouis in Siliana governorate, which involved more than 30 patients over a short period (Bel Hadj et al., 2003). 


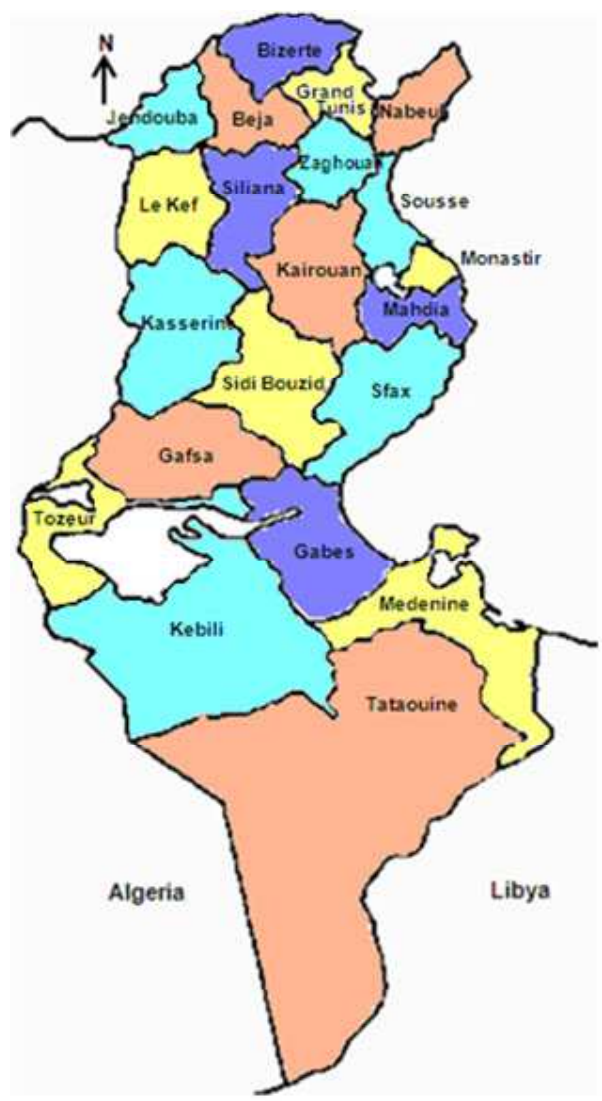

Fig. 2. Map of Tunisia showing its subdivision into 24 governorates (Grand Tunis is composed of 4 governorates).

\begin{tabular}{ccc}
\hline Years & Nb of cases & Median \\
\hline $1945-55$ & 10 & 1.0 \\
$1956-67$ & 17 & 1.4 \\
$1968-78$ & 84 & 8.4 \\
$1979-89$ & 151 & 15.1 \\
$1990-99$ & 217 & 21.7 \\
$2000-10$ & 652 & 59.3 \\
\hline Total & 1131 & 17.1 \\
\hline
\end{tabular}

Table 1. Number of recorded sporadic cutaneous leishmaniasis cases since 1945.

Clinically, SCL is characterized in more than $90 \%$ of patients by a small single ulcerated or lupoid lesion of the face that often lasts longer than one year and up to three years (Bel Hadj et al., 1996; Ben Ismail \& Ben Rachid, 1989; Chaffai et al, 1988; Masmoudi et al., 2007). On a parasitological level, amastigotes of L. infantum are smaller than those of L. major, usually 
less than $3 \mu$, and promastigotes are difficult to maintain on NNN medium (Aoun et al., 2000, 2003).

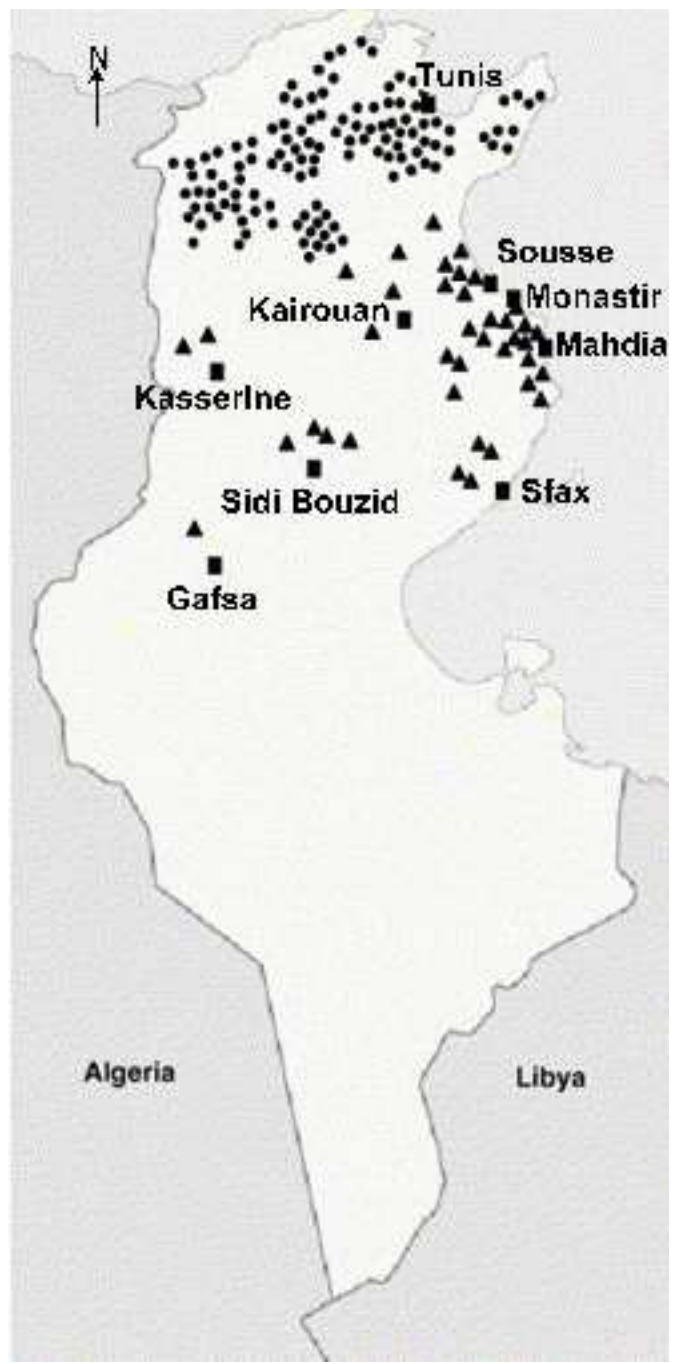

-: corresponds to the classical distribution of the cases; $\mathbf{\Delta}$ : illustrates the emerging distribution of cases.

Fig. 3. Updated distribution of sporadic cutaneous leishmaniasis in Tunisia.

\subsection{The chronic cutaneous leishmaniasis (CCL)}

Formerly known as anthroponotic CL, CCL sporadically occurs in micro-foci located in the south-eastern presaharian and saharian areas of Tunisia. Its distribution is rural, sub-urban and urban; and cases are reported from houses, farms, and even from troglodytes of Tataouine (Tataouine governorate) and Matmata (Gabès governorate), with a median 
annual incidence of 10 cases / year (Figure 4; Ben Ismail \& Ben Rachid, 1989; Ben Rachid et al., 1983, 1992; Chadli et al., 1968). CCL was first reported in 1957 and nearly nothing was known about the disease before this date. In 1979, an outbreak involving 47 individuals arose in Tataouine; and the epidemiological investigation, which included the isoenzymatic typing of strains isolated from the patients, led to the identification of the parasite as the MON 8 zymodeme of L. tropica, named L. killicki, a species previously described in Kenya, Namibia, Yemen and, more recently in Algeria and Libya (Harrat et al., 2009; Rioux et al., 1986; Sang et al., 1994).

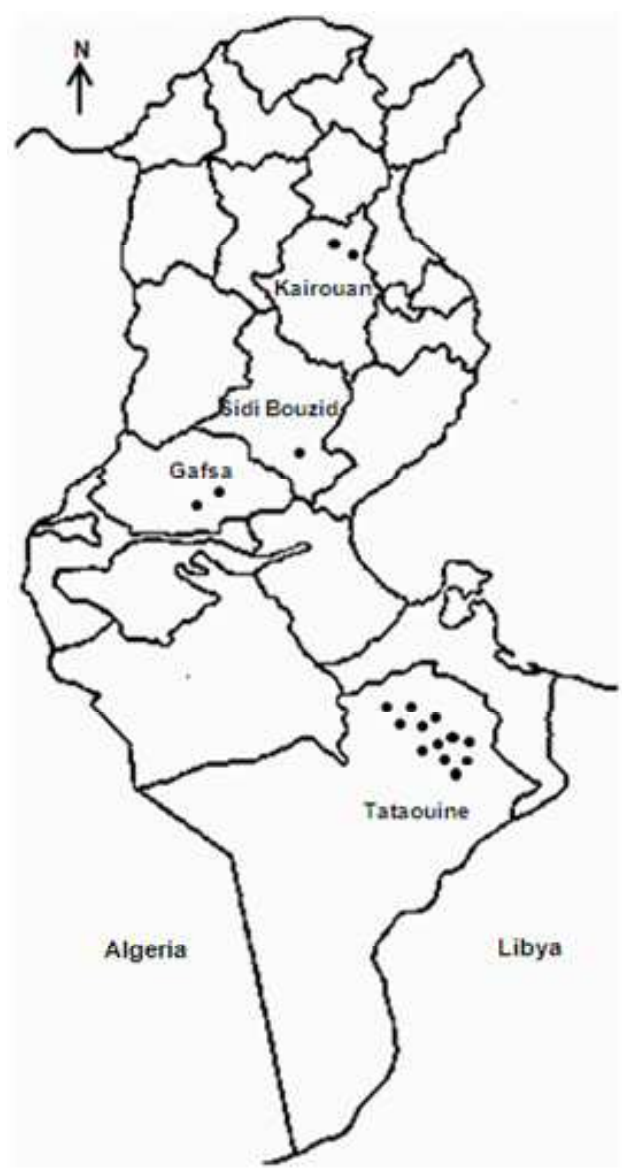

Fig. 4. Actual distribution of chronic cutaneous leishmaniasis.

Surprisingly, over the last decade, cases of CCL were reported in patients originating from areas where this form has never been previously reported, the first case being in a child from Meknassy in Sidi Bouzid governorate (Haouas et al., 2005). Later, additional cases were reported from Kairouan, Gafsa and Siliana governorates, very far from the classical foci of Tataouine (Aoun et al., 2008; Ben Abda et al., 2009; Bouratbine et al., 2005). 
Hence the actual distribution and incidence of CCL need further investigations and obviously should be revised.

L. killicki is transmitted by Phlebotomus sergenti, but the reservoir is still debated. Median age of patients suffering of CCL is 21 years (Ben Abda et al., 2009; Ben Ismail \& Ben Rachid, 1989). Clinically, CCL most often presents as single or very few lesions on the face or limbs, that are dry, extensive, and chronic, lasting for up to six years (Ben Abda et al., 2009; Ben Ismail \& Ben Rachid., 1989; Chaffai et al., 1988; Masmoudi et al., 2007).

\subsection{The zoonotic cutaneous leishmaniasis (ZCL)}

$\mathrm{ZCL}$ is by far the most frequent and the most widely distributed form of CL in Tunisia where it constitutes a major public health problem. It is endemo-epidemic in extended areas of central and southern Tunisia (Figure 5). It is caused by L. major and transmitted by the zoo-anthropophilic Phlebotomus papatasi sandfly which is mainly encountered and caught in and around the rodent burrows, and less in and around human habitations (Ben Ismail et al., 1987b, 1987c; Ben Rachid et al., 1992; Ghrab et al., 2006; Helal et al., 1987). The reservoirs are rodents of the Psammomys and Meriones genera. The main one is P. obesus, a prolific diurnal rodent that is very abundant in arid and subsaharian areas. Its feeding requirements consist exclusively of chenopodiaceae (Salicornia, Salsola, Atriplex) that mainly grow in sandy, humid and salty soils unsuitable for agricultural purposes (Ben Ismail et al., 1987a; Ben Rachid et al., 1992; Fichet-Calvet et al., 2003). Psammonys infection rate may reach $100 \%$. The hygrophilic nocturnal rodents, Meriones shawi and Meriones libycus act as secondary reservoirs and are responsible of the spread of the disease because of their migratory habits. Meriones are granivorous and build their burrows in jujube trees (Zizyphus) surrounding cereal fields and often cause important agricultural damage (Ben Ismail \& Ben Rachid, 1989; Ben Rachid et al., 1992). All Leishmania strains isolated so far from humans, rodents and phlebotomine vectors are of the zymodeme MON 25 (Aoun et al., 2008; Ben Abda et al., 2009; Ben Ismail et al., 1986; Haouas et al., 2007).

ZCL was first described in 1882 in and around Gafsa oases, and termed "clou de Gafsa" (Deperet \& Bobinet, 1884). From this date and up to the beginning of the $20^{\text {th }}$ century, many additional outbreaks were reported in the same area. Then, the disease continued to occur on a very sporadic mode, and nearly disappeared (Chadli et al., 1968; Vermeil, 1956).

In 1982, a large outbreak arose in Nasrallah delegation (Kairouan governorate), near to the recently completed Sidi-Saad dam (Ben Ammar et al., 1984). From there, the disease rapidly spread to cover large rural and sub-urban parts of the central and south-western neighbouring governorates, so that, by 1986, 10 governorates were involved (Figure 6). In season 1991-1992, ZCL extended further south-east to Medenine and Tataouine governorates. All along the outbreak, Sidi Bouzid, Gafsa and Kairouan governorates have remained the leading areas in terms of incidence (Anonymous). However, from the early 1990s and up to date, Tataouine, Tozeur, Médenine, Kébili, Gabès, Sfax and Kasserine have emerged as active and stable foci (Figure 5). In the last few years, some level of ZCL spread towards the north (Siliana, Béja, Le Kef, Tunis and Zaghouan governorates) was registered, which is somewhat surprising (Ben Abda et al., 2009).

The number of annual recorded cases rapidly grew from 182 cases in 1982 to $>18000$ cases by $1987,>65000$ cases by 1999 . Up to date, $>120000$ cases were reported and the epidemic is still going on. It should be mentioned however, that the actual number of cases is supposed to be underestimated and would exceed 150000 cases (Chahed et al., 2002). The number of annual recorded cases greatly varied and ranged from 1129 cases in 1995 to > 15000 in 2004, 


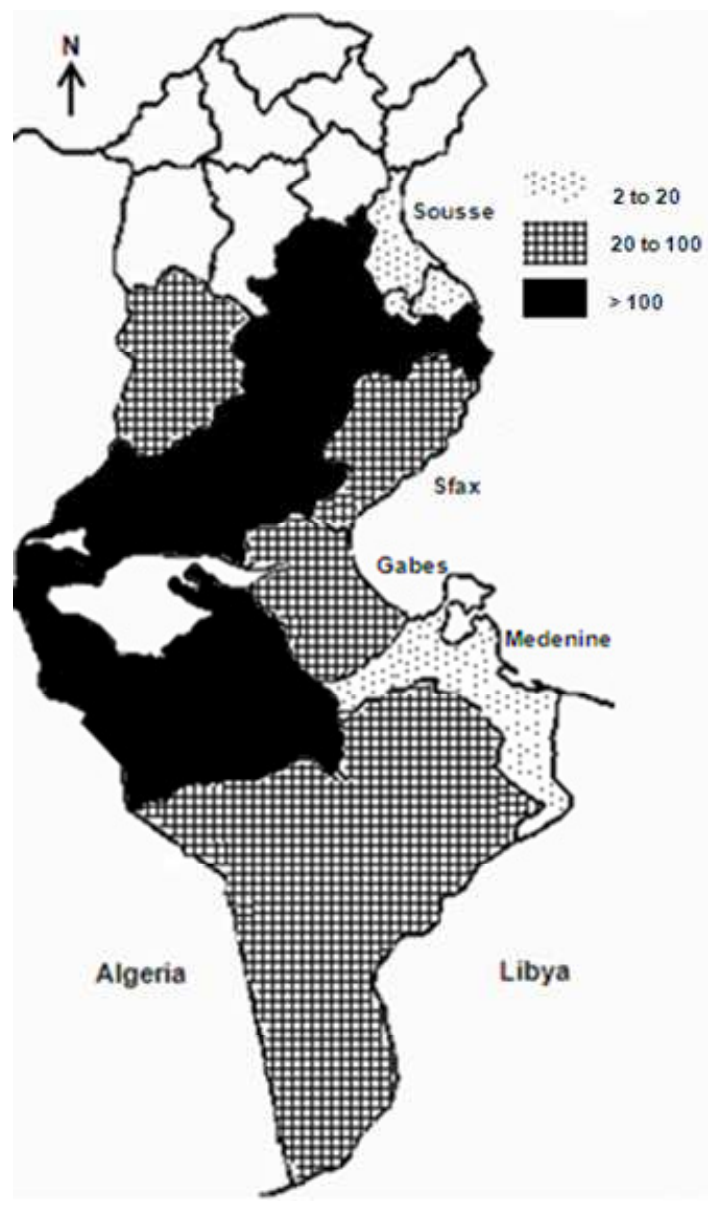

Fig. 5. Distribution of zoonotic cutaneous leishmaniasis according to incidence ( expressed as $\% 0000)$.

with an average of 4700 cases/year (Figure 7). The annual incidence showed the same fluctuations. It ranged between $3 \% 000$ in the less affected areas and $>500$ in Kairouan, and > 1000 in Gafsa and Sidi Bouzid in 2004 (Anonymous). These fluctuations are at least in part related to the dynamics of rodents' populations. It was demonstrated that the distribution of $P$. obesus is of paramount importance in the epidemiology of the human disease (Ben Ismail et al., 1987a; Ben Ismail \& Ben Rachid, 1989; Ben Salah et al., 2007; Fichet-Calvet et al., 2003). On the other hand, control programmes are undoubtedly very effective and beneficial in terms of incidence. Indeed, a rodent control project, consisting of ploughing lands with growing chenopods and reafforestation with acacia and other plants was launched in 1992 in Sidi Bouzid city and suburbs that resulted in a dramatic decrease in the incidence of the disease in the area; but the intensity of the epidemic grew again as soon as the control programme stopped (Figure 7). From the mid 2000s, similar control measures have been carried out again in Sidi Bouzid and then in Sidi El Heni 
delegation which is the main transmission focus in Sousse governorate, and led to an obvious decrease of incidence in both foci.

The ongoing outbreak that started in 1982 near the Sidi-Saad dam may be explained by the interruption, as a result of the construction of the dam, in the flooding that frequently occurred in the area and used to decimate a high proportion of rodents every year. In addition, the enrichment of the area's ground water helped the chenopodiaceae to grow abundantly, thereby increasing the food source of Psammomys. On the other hand, Atriplex, a plant grown in large quantities as a sheep fodder is much appreciated by Psammomys. Furthemore, humidity created by the dam is highly suitable for the sandflies.

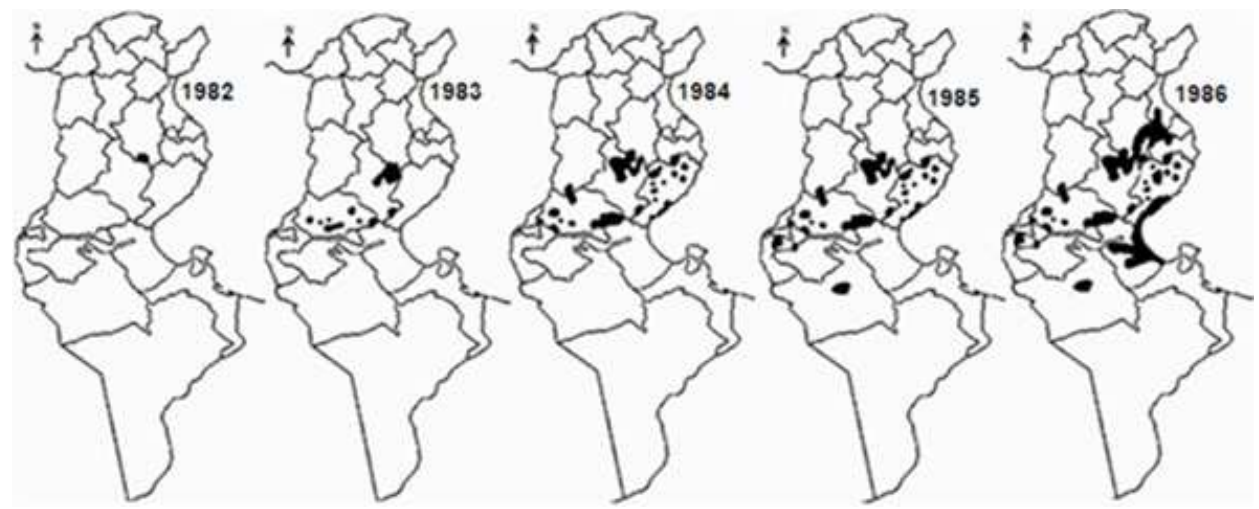

Fig. 6. Spread of zoonotic cutaneous leishmaniasis during the period 1982- 1986 (Ben Ismail R., unpublished).

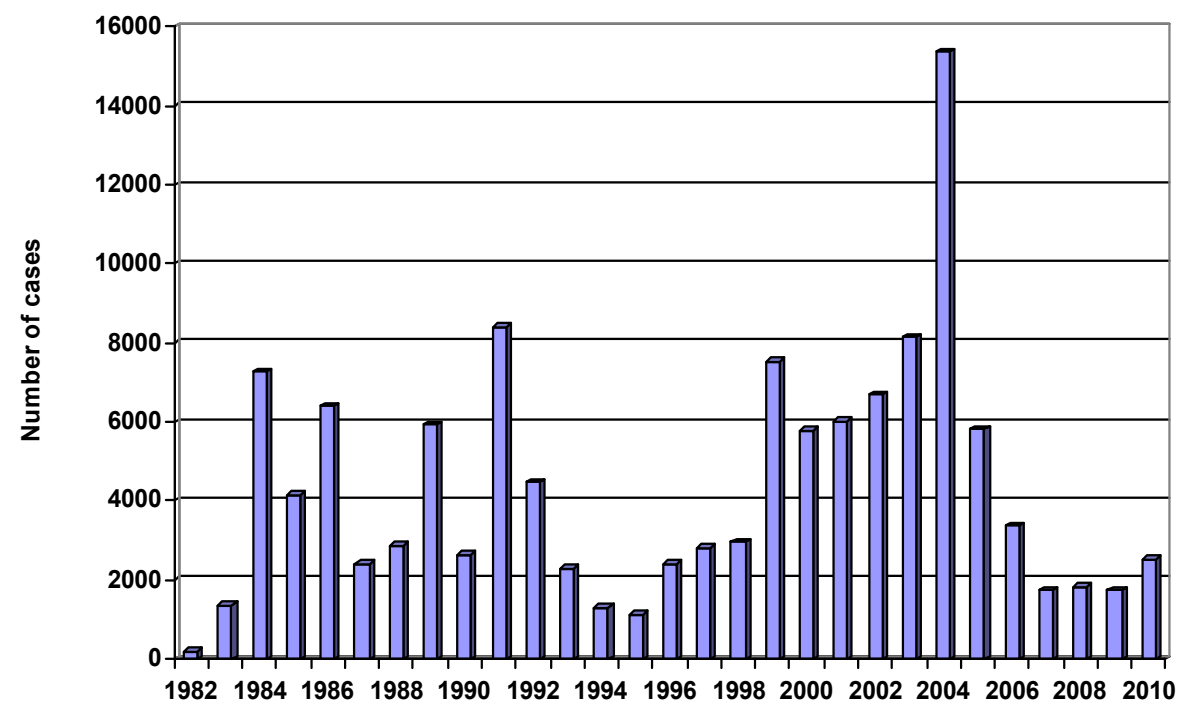

Fig. 7. Annual number of reported zoonotic cutaneous leishmaniasis cases at the national level from 1982 up to 2010. 
One of the characteristics of ZCL is its marked seasonal occurence as most cases are observed between october and january (Ben Ismail \& Ben Rachid 1989; Ben Rachid et al., 1992).

Clinically, ZCL most often presents as multiple, inflammatory ulcers on the face and the limbs that usually scar in less than 6-8 months, and affects all ages with a median of 24 years (Ben Abda et al., 2009; Ben Ismail \& Ben Rachid, 1989; Chaffai et al., 1988; Masmoudi et al., 2007; Zakraoui et al., 1995).

\subsection{Visceral leishmanasis (VL)}

VL has been known to sporadically occur in Tunisia, since 1903 where the first case of mediterranean VL was described in a child living in the suburbs of Tunis. The disease is caused by Leishmania infantum, mostly zymodeme MON 1 and to a lesser extent zymodemes MON 24 and MON 80 (Aoun et al., 2001, 2008; Bel Hadj et al., 1996, 2000, 2002; Ben Ismail et al., 1986; Haouas et al., 2005; Kallel et al., 2008b). It is transmitted by Phlebotomus perniciosus sandfly, and the dog is the exclusive reservoir, with an infection prevalence rate ranging from 5\% to $26 \%$ (Ben Ismail et al., 1986; Ben Rachid et al., 1992; Bouratbine et al., 1998).

Since 1903, 2449 VL cases were reported in Tunisia (Table 2).

\begin{tabular}{ccc}
\hline Period & Nb cases & Median/year \\
\hline $1903-1956$ & 151 & 2.8 \\
$1957-1967$ & 142 & 12.9 \\
$1968-1981$ & 178 & 12.7 \\
$1982-1989$ & 578 & 72.3 \\
$1990-2000$ & 720 & 65.5 \\
$2001-2010$ & 680 & 68.0 \\
\hline Total & 2449 & 22.7 \\
\hline
\end{tabular}

Table 2. Number of visceral leishmaniasis cases reported in Tunisia (1903-2010)

Up to 1981, incidence was low to moderate and nearly all cases were reported from Zaghouan, North-West (Le Kef, Béja, Jendouba, Siliana), Tunis and Sousse governorates, located in the humid, sub-humid and semi-arid zones (Anderson et al., 1934, 1938; Ben Ismail et al., 1986; Ben Rachid et al., 1983; Chadli et al., 1968; Khaldi et al., 1991; Nicolle, 1912; Vermeil, 1956). From the early 1980s, the incidence markedly increased and the disease progressed towards the south, mainly to Kairouan governorate and to a lesser extent to Sfax, Sidi Bouzid, Kasserine and Tozeur governorates, together with an increase in canine leishmaniasis (Ayadi et al., 1991; Bel Hadj et al., 1996; Ben Salah et al., 2000; Besbès et al., 1994; Bouratbine et al., 1998; Chargui et al., 2007; Pousse et al., 1995). Indeed, from the 1980s, the region of Kairouan emerged as a highly active VL focus, and by 1991-1992 it was recognized as the most active one, with 30 to $55 \%$ of reported cases (Anonymous).

The distribution of VL is given in figure 8. Highest number of cases was reported in 1922 (n $=130), 1993$ and $2006(n=122)$, and $2005(n=120)$. It is worth mentioning that VL has nearly disappeared between 1974 and 1980, as a result of the anti-malaria campaign which included extensive insecticide spraying (Ben Rachid et al., 1983). The disease sporadically occurs in rural and to a lesser extent in suburban areas and mainly affects children under five years, cases in immunocompetent adults being less than 5 \% (Ben Ismail \& Ben Rachid, 1989; Ben Rachid et al., 1983; Besbès et al., 1994; Bouratbine et al, 1998; Hammoud et al., 
2004; Pousse et al. 1995). In HIV Tunisian patients, VL is infrequent; it is best diagnosed by PCR (Kallel et al., 2007).

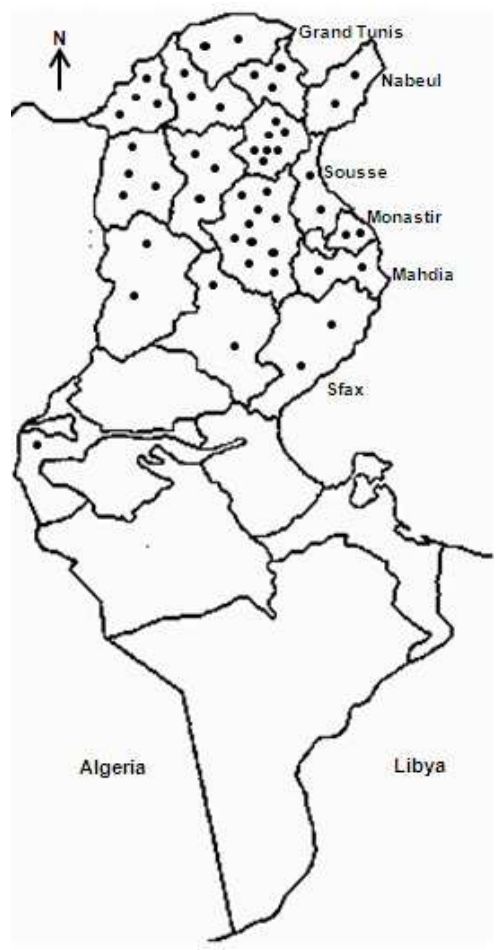

Fig. 8. Actual distribution of visceral leishmaniasis in Tunisia.

\section{Materials and methods}

The laboratory of parasitology of Sousse, the third major Tunisian city which is located in the central, coastal part of Tunisia, was first created in 1986. It can be considered as a central laboratory ensuring the diagnosis of parasitic diseases' cases including leishmaniasis, sent by generalists, dermatologists, pediatricians or hematologists either from the same hospital or other hospitals mainly from governorates of central Tunisia like Kairouan, Sidi Bouzid and Mahdia. Results are usually sent back to the referring doctors so the patients can be managed as appropriate. Since its creation, the laboratory has been involved in the diagnosis of all forms of leishmaniasis.

For purposes of this retrospective study, VL and CL patients' data, including age, sex, geographical origin and the likely place of contamination, clinical presentation and evolution without or after treatment were collected.

\subsection{Diagnosis of cutaneous leishmaniasis}

The diagnosis of CL is usually achieved by the demonstration of amastigotes in Giemsastained smears from the fluid obtained by scraping the edges of the cutaneous lesion with a 
sterile lancet. In addition, the size of the identified Leishmania is carefully evaluated, because small amastigotes $(<3 \mu)$ are evocative of L. infantum and L. killicki rather than L. major whose amastigotes are larger. Over the last decade, lesions evocative of CL but found negative in direct examination were further submitted to PCR technique, known to be more sensitive.

\subsection{Diagnosis of visceral leishmaniasis \\ 3.2.1 Parasitological diagnosis}

Diagnosis of VL is usually based on the demonstration of amastigotes in Giemsa stained bone-marrow aspirates. However, in our laboratory, bone-marrow smears are mainly carried out and read in doubtful cases, because they usually are performed and interpreted by the haematologists and sometimes the pediatricians themselves and the results of the examination are later sent to us together with sera specimens.

For the purpose of parasitological diagnosis of VL, since 1996, we have been using the cytoconcentration of peripheral blood according to the technique of Petithory et al, 1997. Cytoconcentration is usually practiced first, and when positive the painful bone marrow aspiration is no more needed and the diagnosis of VL is established.

\subsubsection{Serodiagnosis of leishmaniasis}

All sera from suspected or confirmed VL cases are sent to our laboratory for serodiagnosis. Our reference technique is the fluorescent antibody test (FAT). It is carried out by using Leishmania-spot $\mathrm{IF}^{\circledR}$ slides (bioMerieux, France) on sera serially diluted starting from 1/100. Sera showing fluorescence at $\geq 1 / 200$ dilution are considered positive.

In addition to FAT, we have been using, since 2003, the rK39 dipstick test (DST). The first one we used was from Inbios International, USA (kalazar detect ${ }^{\circledR}$ ). Then, since 2007 and up to date, we have been using the Dia.Med IT Leish ${ }^{\circledR}$ (Dia Med, Switzerland), according to Saghrouni et al., 2009.

\subsection{Culture of Leishmania}

Our laboratory has mainly been involved in the culture of dermotropic Leishmania, even though isolates from VL bone-marrow aspirates were occasionally cultured.

Culture was mainly carried out for the purpose of typing strains by isoenzyme electrophoresis (IEE) technique. Media we have been using are the NNN (Nicolle Novy Mc Neal), the BHI (brain heart infusion agar) and the CRS (coagulated rabbit serum), the last being best for cutaneotropic L. infantum strains. Leishmania isolates were typed either in the IEE unit of the LEEP or in the laboratory of parasitology of the Faculty of Pharmacy, Monastir, where an IEE unit was set up in 2001.

\subsection{Molecular biology}

Up to 2008, our laboratory was not equipped for molecular biology techniques. In 2007, as part of a collaborative project on "molecular tools for accurate diagnosis and better assessment of leishmaniases", codirected by the LEEP and our own laboratory and financed by the IAEA, a molecular biology unit was set up in our department and has just started working. In the meanwhile we have been collaborating with the molecular biology unit of the LEEP, mainly for identifying Leishmania strains. The first study, conducted in 2005, aimed at identifying strains isolated from patients suspected for having SCL, by using K-DNA-PCR according to Smyth et al., 1992 and PCR-RFLP according to Guerbouj et al., 2001 (Ben Said et al., 2006). 
Later, additional strains isolated from CL patients were typed by a novel Multiplex PCR (Saadi et al., in preparation) as part of the IAEA project that is still ongoing.

In addition, specimens from patients with lesions highly evocative of CL but found negative in parasitological examination were addressed for PCR to the laboratory of parasitology of the Faculty of Pharmacy, Monastir, where a molecular biology unit has just been set up. PCR was performed according to Chargui et al., 2005.

\section{Results}

\subsection{Cutaneous leishmaniasis}

Over the 25 year period study, 4329 patients were investigated for CL. Most of them were referred to our laboratory by the service of Dermatology of Farhat Hached hospital, Sousse. Leishmania parasites were demonstrated in 2087 cases (48.2\%). In addition, out of 86 PCR performed on samples found negative in direct examination of dermal Giemsa stained smears, 17 were positive. So, the total number of CL cases diagnosed during the study period was 2104. Most of them were diagnosed during the last decade.

Out of the 2104 diagnosed cases 50 were confirmed or very likely SCL form. Fourteen came from areas known to be endemic for SCL (Le Kef, Jendouba, Siliana, Zaghouan and Bizerte governorates). The remaining 36 cases were from areas located in central Tunisian governorates where SCL has never been described: 13 were from Monastir, 12 from Sousse, 6 from Mahdia and 5 from Kairouan. Out of the 36 cases, 13 originated from areas known to be endemic for ZCL, in Kairouan, Mahdia and Sousse governorates. The age of patients ranged from to 5.5 to 63 years (median $=28.5$ years). Twenty six were males and 24 were females (sex ratio $\mathrm{M} / \mathrm{F}=1.08$ ).

In three patients, the isolate proved to be L. killicki. The first patient was a 5 year old child from Meknassi in Sidi Bouzid governorate where CCL was unknown. The second was a 30 year old woman from Ghomrassen, known to be endemic for CCL. The third patient was a 21 year old woman who came from Nasrallah, one of the most active ZCL foci in Kairouan governorate and from where no CCL cases were reported before.

All the remaining 2051 patients were suffering from ZCL. 1182 were females and 869 were males (sex ratio $\mathrm{F} / \mathrm{M}=1.36$ ). Their age ranged from 1 month to 90 years (median $=28$ years). The annual distribution of ZCL cases diagnosed over the 25 year period is shown in figure 9. The number of cases ranged from 5 in 1997 to 443 in 2004.

The place of contamination could be ascertained in 1873 out of the 2051 patients. In the 178 remaining cases, the geographical origin of contamination could not be determined with certainty because of multiple displacements of patients across two, three or more endemic areas. In addition, some patients were originating from Libya and Algeria and were not included in the analysis of the spatio-temporal distribution of ZCL cases.

The distribution of the $1873 \mathrm{ZCL}$ cases according to the area where the contamination took place is given in table 3. Most of the patients came from Sidi Bouzid $(610=32.6 \%)$, Mahdia $(494=26.4 \%)$, Kairouan $(369=19.7 \%)$, and Sousse $(306=16.3 \%)$ governorates .

The distribution of cases according to delegations inside the four governorates mentioned above is shown in figure 10, and the annual distribution of diagnosed cases in figure 11. According to seasonal distribution 1745 (85.1 \%) cases were diagnosed between October and February. All confirmed CL patients were treated with local or parenteral Nmethylglucamine antimoniate (glucantime ${ }^{\circledR}$ ) together with cryotherapy in those with few lesions. Most of treated patients responded well to antimonial treatment, and scarring of 


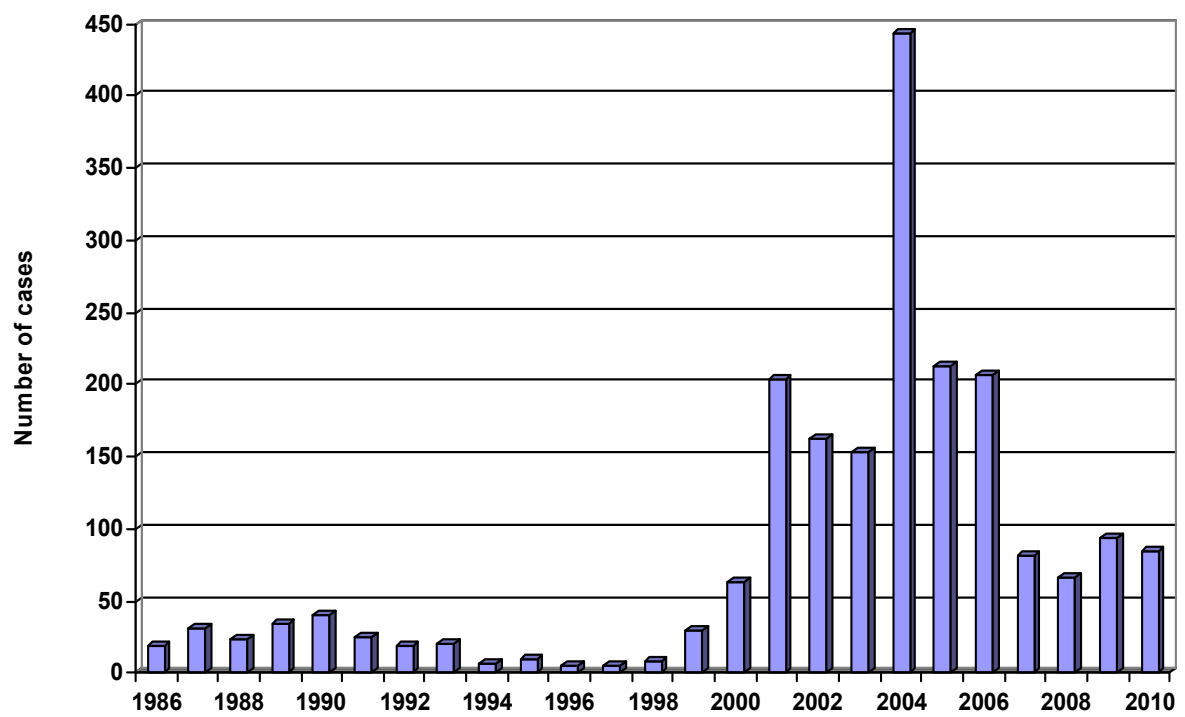

Fig. 9. Annual distribution of 2051 zoonotic cutaneous leishmaniasis cases (1986-2010).

\begin{tabular}{|c|c|c|c|}
\hline Governorate & Delegation & Nb/delegation & $\mathrm{Nb}$ (\% / governorate) \\
\hline \multirow{4}{*}{ Sidi Bouzid } & Ouled Haffouz & 453 & \\
& Jelma & 41 & $610(32.6 \%)$ \\
& Sidi Bouzid city & 33 & \\
& Others & 88 & \\
Mahdia & Chorbène & 321 & $494(26.4 \%)$ \\
& Souassi & 54 & \\
& Hbira & 54 & \\
& Ouled Chamekh & 51 & \\
& Others & 14 & $369(19.7 \%)$ \\
Kairouan & Nasrallah & 127 & \\
& Bouhajla & 56 & \\
& Kairouan south & 45 & $306(16.3 \%)$ \\
\hline Sousse & Hadjeb layoun & 42 & \\
& Others & 99 & \\
\hline Others : Monastir, & Sidi El Heni & 241 & $94(5 \%)$ \\
Gafsa, Kasserine, Sfax, & Msaken & 33 & 1873 \\
Tataouine, Tozeur, & Others & 32 & \\
Gabes, Kébili & & - & \\
\hline TOTAL & - & - & \\
\hline
\end{tabular}

Table 3. Distribution of 1873 zoonotic cutaneous leishmaniasis cases according to governorate and delegation. 


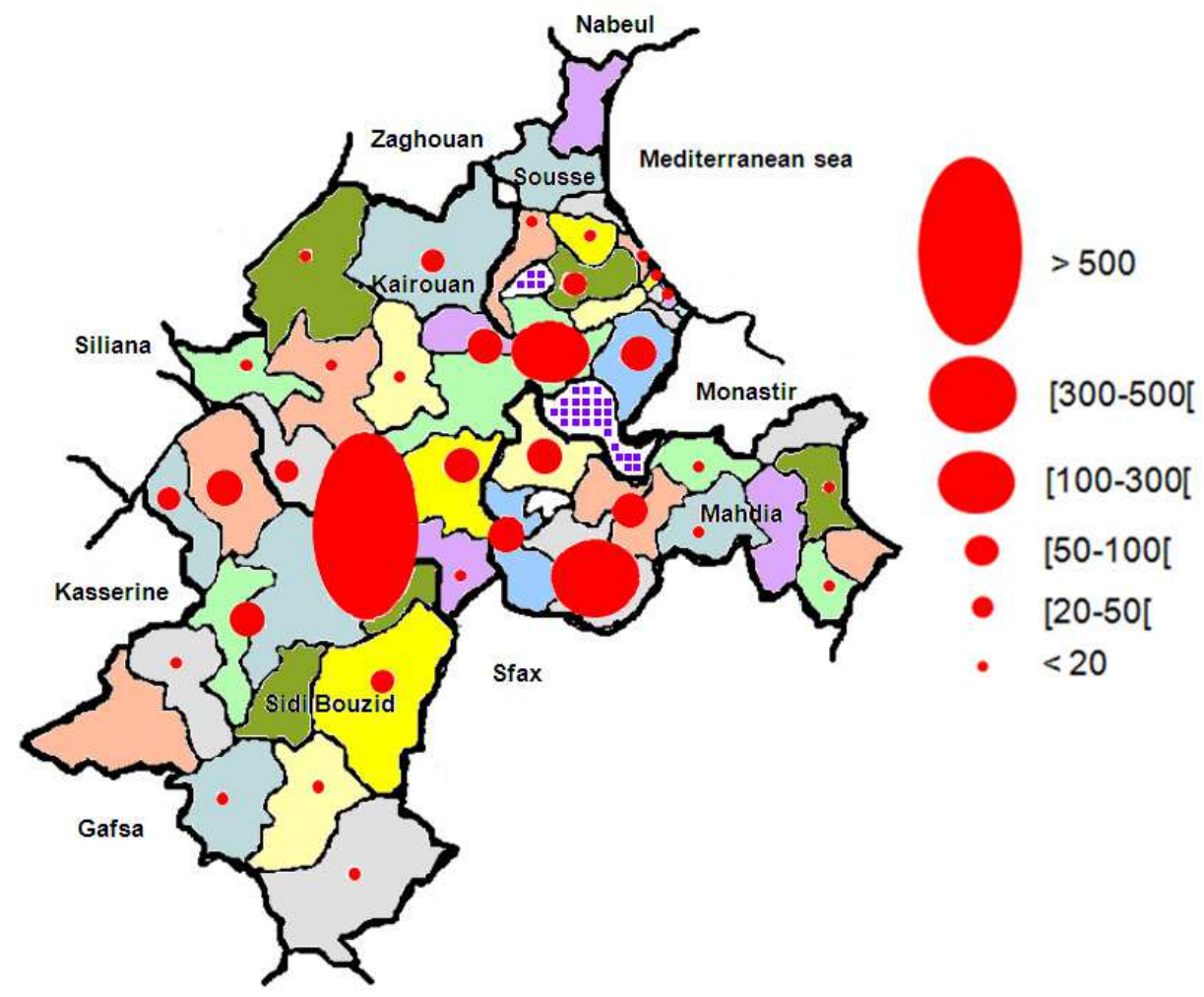

Fig. 10. Distribution of 1779 zoonotic cutaneous leishmaniasis cases diagnosed over the 25 year period originating from Sidi Bouzid, Mahdia, Kairouan and Sousse. The dots represent the number of cases. The limits of the governorates are shown in bold lines. The administrative district subdivisions are illustrated by different colours in each governorate.

lesions was obtained in a few weeks (one to three) after the treatment was initiated. However, in some patients, the outcome was unexpectedly atypical in that the lesions took much more delay to heal as demonstrated by the persistence of Leishmania in direct examination. In some adequately treated patients, the lesions persisted longer than one year and up to 4.5 years in one of them. In another patient, nearly 100 glucantime ${ }^{\circledR}$ injections were needed before the lesions resolved. In some additional cases, new lesions appeared while the patient was under specific treatment for previous ulcers. On the other hand, in many patients treated with in situ antimonial infiltrations, sporotrichoid nodules developed a few days or weeks later, next to the treated lesion. 


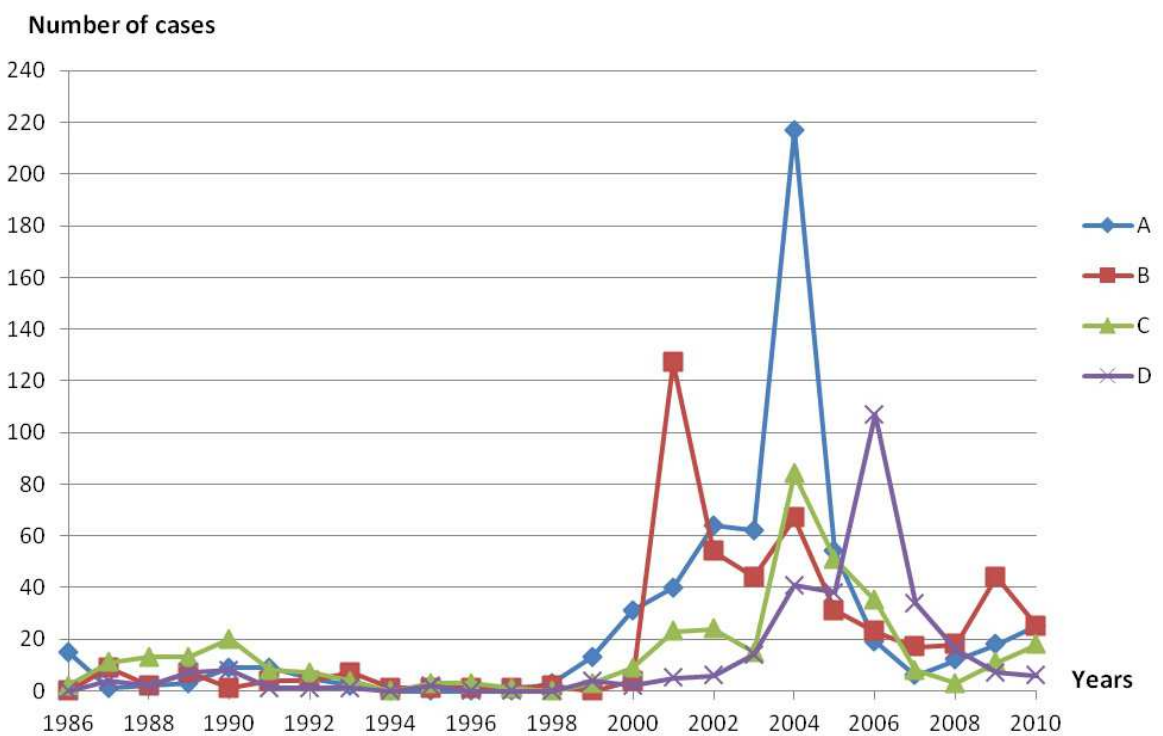

Fig. 11. Annual distribution of 1779 zoonotic cutaneous leishmaniasis cases in Sidi Bouzid (A), Mahdia (B), Kairouan (C) and Sousse (D) governorates (1986 to 2010).

\subsection{Visceral leishmaniasis}

Up to 2010, 2784 serum samples were addressed to our laboratory for suspected VL cases. Anti-Leishmania antibodies were demonstrated in 944 sera. FAT and rK39 DST were positive in $944(99.2 \%)$ and $822(87.1 \%)$ cases respectively. In all positive patients, VL was confirmed by the demonstration of amastigotes in bone marrow and/or cytocentrifuged blood and/or favourable outcome under antimonial treatment. In 8 confirmed VL cases, both serological tests were negative.

Thus, the total number of VL cases diagnosed over the 25 year period is 952 .

Three hundred and eight blood samples were investigated by the cytoconcentration technique. Among them, 201 were from confirmed VL patients, and amastigotes were demonstrated in $88(43.7 \%)$ of them. In six cases, bone marrow examination was also negative. Apart from the confirmed VL FAT negative cases, all the remaining negative sera were from patients suffering from diseases other than VL, mainly leukaemia and various haematological disorders. Nine hundred and thirty four of the VL patients were children, aged 2 months to 14 years (median: 26.8 months). Eighteen were adults aged 19 to 39 years (median: 25.9 years); one of them was a HIV+ woman. The number of annually diagnosed cases ranged from 14 cases in 2004 to 83 cases in 2005. The highest proportion of VL cases $(60 \%)$ was from Kairouan governorate, known to include the most active foci of VL in Tunisia, followed by Sousse governorate and, to a lesser extent from other areas in central Tunisia (Mahdia, Monastir, Kasserine).

All confirmed VL patients were treated with glucantime ${ }^{\circledR}$, usually a single 21 to 28 day course. The outcome was favourable in the majority of them. Death occurred in 18 (1.9\%) patients. All were children. In 4 of them, no response to antimonials was observed despite an adequate treatment regimen. They were assumed to be resistant to antimonials even 
though the resistance could not be assessed by in vitro testing of the strain. In an additional child, initially treated by three successive courses of glucantime ${ }^{\circledR}$, healing was ultimately obtained with ambisome ${ }^{\circledR}$ (liposomal amphotericin B).

\subsection{Typing of Leishmania strains}

Over the 25 year study period 103 Leishmania strains were typed by either IEE or PCR or both. More than 150 isolates were in vitro cultured. Fifteen of them were from bone-marrow aspirates in VL cases. All were typed by IEE and found to be L. infantum. Most cultured isolates were from CL patients. Eighty one of them could be maintained in culture media, cryopreserved and typed by IEE. The remaining isolates were either lost after repeated subculture or contaminated during sampling or subculturing. It should be mentioned that strains addressed to the laboratory of Monastir, were typed and identified at the zymodeme level, whereas those typed in the LEEP were only identified at the species level.

Sixty four isolates were typed by molecular techniques: 4 were typed by K-DNA-PCR and PCR-RFLP, and 60 by multiplex PCR.

Overall, 88 CL strains were typed by either IEE or PCR technique: 7 were L. infantum, 3 were L. killicki and 78 were L. major. All L. major strains that were typed at the zymodeme level were found to be L. major MON 25.

\section{Discussion}

One of the main characteristics of the four leishmaniasis forms occurring in Tunisia is their changing epidemiological pattern, which has continuously been described over the last 30 years. These changes mainly consisted of the spread of all forms of the disease from their initial endemic foci towards neighbouring or farther areas.

The VL which has long been confined to the northern parts of Tunisia showed a noticeable spread towards the central and southern parts of the country, where the disease has never been previously reported. The Kairouan governorate where VL was unknown till 1980, has progressively emerged as a highly endemic area and by the early 1990s, it became the most active focus in terms of incidence (Anonymous; Bel Hadj et al., 1996; Besbès et al., 1994; Bouratbine et al., 1998). These findings contrast with earlier periods where VL was mainly reported from Zaghouan, North-western and Tunis governorates and to a lesser extent from the central coastal region (Sousse) (Anderson et al., 1938; Ben Ismail et al., 1986; Ben Rachid et al., 1983; Chadli et al., 1968). In the same time, VL progressively spread further south to southern and central western governorates (Sfax, Sidi Bouzid, Kasserine, Tozeur) (Ayadi et al., 1991; Chargui et al., 2007). While spreading, the VL incidence markedly increased from a median of 12 to 68 annual recorded cases, $50 \%$ of them being from Kairouan foci.

Similar trends were described in SCL which, up to 1980, was very rarely reported south to the Tunisian ridge ("dorsale"). From the early 1980s, and up to date, SCL has continuously been reported from central and southern parts of the country (Aoun et al., 2000, 2008; Ben Saïd et al., 2006; Kallel et al., 2005, 2008a).

ZCL was first reported on the end of the 19th century causing large outbreaks in Gafsa and neighbouring areas. Later, it has nearly disappeared for half a centrury; but reappeared again in 1982 causing a widespread epidemic that is still going on and constitutes a major public health problem in extended areas of the country, with up to date more than 150000 cases (Anonymous; Ben Abda et al., 2009; Ben Ismail \& Ben Rachid, 1989). 
CCL, known to be confined to limited areas in the presaharian region of Tataouine, has itself shown spread towards areas far from its original endemic foci, up to Kairouan governorate (Aoun et al., 2008; Haouas et al., 2005).

The described changes are supposed to mainly originate in the agricultural development and the ecological transformations that occurred in the concerned areas and led to a marked increase in irrigated surfaces that in turn helped the reservoirs (mainly rodents) and vectors to abundantly proliferate, and created biotopes very suitable for the Leishmania cycles to establish and amplify (Aoun et al., 2008; Ben Abda et al., 2009; Ben Salah et al., 2007). In addition, urbanization of previously rural areas made the populations' access to medical facilities easier, and consequently more and more leishmaniasis cases could be detected and diagnosed. The impact of climate change and variability on leishmaniasis (due to el Niño) was shown in Colombia and is associated to shifts in insect and animal distributions (Cardenas et al., 2008). This phenomenon was also shown to impact on the incidence of VL in Brazil and models were established to predict high risk years for VL (Franke et al., 2002). In Tunisia, the relationship between climate variability and leishmaniasis is not well studied. However, incidence rate of VL was shown to be positively correlated with mean yearly rainfall and continentality index; a rainy year is followed 2 years later by an increase in VL cases likely modulated by the intensity of transmission to dogs and by the influence on sandfly abundance (Ben-Ahmed et al., 2009). Distribution of sandflies classically associated to VL was also shown to be dependent on bioclimate (Zhioua et al., 2007), likewise for the distribution of Phlebotomus papatasi, the vector of ZCL (Chelbi et al., 2009).

Knowledge on the epidemiological patterns and trends in leishmaniasis has much increased over the last 3 decades mainly because of a better identification of the Leishmania species involved in the natural cycles of the parasite. This knowledge greatly benefited of the availability of techniques used in typing isolates obtained from humans or from reservoirs and sandflies. In this respect, IEE or molecular techniques allowed a more precise identification of the Leishmania at the species, zymodeme and genomic (schizodeme) level (Ben Hammouda et al., 2000; Ben Ismail et al., 1992; Ben Said et al., 2006; Guerbouj et al., 2007; Guizani et al., 1993, 1994a, 1994b; Guizani et al., 2002; Hanafi et al., 2001; Kallel et al., 2008b).

As far as zymodemes are concerned, it was shown that L. major was much more homogeneous than L. infantum. Indeed, all L. major strains obtained from humans, rodents and sandflies proved to be identical to the L. major MON 25 reference strain (Aoun et al., 2008 ; Ben Ismail et al., 1986; Haouas et al., 2007 ; Kallel et al., 2005). In contrast, at least three L. infantum zymodemes occur in Tunisia : i) the MON 1, mainly causing VL and to a lesser extent SCL ; ii) the MON 24, the most common agent of SCL, that also causes VL ; iii) the MON 80, which is very rarely isolated (Aoun et al., 1999, 2008; Bel Hadj et al., 2000, 2002; Gramiccia et al., 1991; Haouas et al., 2007). These findings show that a single zymodeme may cause quite different diseases; and raise the as yet poorly documented question of pathogenesis and virulence of strains in cause. In addition, it was shown that the distribution of both MON 1 and MON 24 L. infantum zymodemes was different according to the geographical areas the patients originated from. Indeed, L. infantum MON 24 zymodeme was more frequently reported in VL cases from Kairouan governorate as compared to northern VL foci where MON 1 zymodeme is predominant. This was attributed to the emergent character of Kairouan foci which may favour and select atypical or rare variants (Aoun et al., 2008; Ben Abda et al., 2009). Involvement of different 
sandfly species in transmission of different L. infantum parasites can not be excluded (Guerbouj et al. 2007). It is well established that different sandfly species belonging to the sub-genus Larroussius are involved in the transmission of L. infantum; in Tunisia clear association between sandfly species and bioclimate was demonstrated and presence of species of this subgenus in the different bioclimatic zones allowed explaining the extension of VL (Zhioua et al., 2007).

The reservoir of L. killicki is still debated. Some findings argue for its zoonotic origin as the disease is hypoendemic and frequently reported in rural populations. In addition, L. killicki in Kenya was isolated from hyracoides (Sang et al., 1994). However, CCL has also been reported from urban areas and from regions where L. major ZCL is highly prevalent and additional CCL cases were probably misdiagnosed. So, the CCL may be more frequent than previously thought. On the other hand, it was hypothesized that competition between $L$. major and L. killicki may lead to some degree of pressure exerted by the first species with a subsequent reduction in the incidence of the second one (Aoun et al., 2008). However, parasite identification still remains circumstantial; parasite isolation from cutaneous lesions is often contaminated by overgrowing microorganisms. In this situation, isolating and typing of much more additional strains is highly needed, in order to get further insight in the knowledge of the concerned Leishmania cycles.

Even though IEE has been demonstrated to be quite efficient in identifying isolates and still constitutes a reference tool, molecular techniques would be more relevant in assessing variability of strains, as even minor genomic variations may have important consequences on the epidemiological and the clinical levels. An additional advantage of the molecular techniques is their rapidity in that culture of isolates is no more needed. On the other hand, they are much adapted for both diagnostic (PCR, Multiplex PCR, Real time- PCR) and epidemiological (PCR-RFLP, Multiplex PCR, RAPD) purposes (Aoun et al., 2008; Bel Hadj et al., 2002; Ben Ismail et al., 1992; Ben Said et al., 2006; Chargui et al., 2005; Guerbouj et al., 2007; Guizani et al., 1994a, 1994b; Guizani et al., 2002; Hanafi et al., 2001; Saadi et al., in preparation). In addition, molecular techniques are specific and highly sensitive, allowing identification of parasite species hard to isolate or to maintain in vitro in culture or too scarce to be detected or cultured. It has been supposed that the dog is the reservoir of L. infantum MON 24 zymodeme and P. perfiliewi the phlebotomine vector. However, isolation of this zymodeme from either the dog or the sandfly has been unsuccessful, making the hypothesis questionable (Aoun et al., 2008). In this situation, molecular techniques would be much more suitable for this purpose. Using DNA tools, P. langeroni was found infected with $L$. infantum in an active transmission focus of SCL (Guerbouj et al., 2007). It may be concluded from all these findings that identification and typing of isolates are much needed in order to best assess the epidemiology and to investigate the diversity and changing patterns of leishmaniasis.

The incidence of leishmaniasis as reflected by the annually reported cases at the national level together with our own findings was shown to highly vary and fluctuate over the 25 year period study. These fluctuations were attributed first to the dynamics of the reservoirs' populations and sandflies, as a consequence of climatic variations, environmental and ecological changes occurring in the endemic areas (see section 2); and second, to the immunization, through the repeated outbreaks, of the infected human populations, that progressively makes previously infected people in the endemic area less receptive to the infection. This was best demonstrated in the ZCL form (Ben Salah et al., 2007). 
In Tunisia, human activities, agricultural development and the subsequent ecological changes mainly benefited to rodents which dramatically proliferated in areas where their populations were previously too low for the Leishmania cycle to be completed. This can explain that ZCL is by far the predominant and the most widespread form of leishmaniasis in Tunisia, in terms of both incidence and geographical distribution. In addition, no sustained control programme for ZCL was carried out in most endemic areas, because of the difficulties that arose in the organization and the feasibility of such programmes. This made the ZCL epidemics still going on. It is worth mentioning however that control projects may be successful, as demonstrated by the results of those launched in 1992 in Sidi Bouzid area and again in the mid 2000s in Sidi Bouzid and Sidi El Heni, that led to an obvious decrease in the ZCL incidence over the mid 1990s in Sidi Bouzid and the last few years in both regions.

As compared to SCL, the spread of VL has been more important and obvious. This finding was related, among other factors, to the ecology of the phlebotomine vectors as it was shown that $P$. perniciosus (sub-genus Larroussius), the vector of MON $1 \mathrm{~L}$. infantum zymodeme is more resistant to dry climate as compared to $P$. perfiliewi, the presumed vector of MON 24 zymodeme (Aoun et al., 2008 ; Ben Abda et al., 2009). Given the fact that presence and distribution of the different sandfly species generally associated to L. infantum transmission explained extension of VL (Zhioua et al., 2007) and that the extensions seem to concern in majority MON 24 parasites (Aoun et al., 2008; Ben Abda et al., 2009; Kallel et al., 2008a), explanations may well relate to parasite features not accounted for by the mere attribution to zymodemes and/or to differential distribution of reservoirs yet to identify.

Even though molecular techniques namely PCR and its variants have been increasingly used in the diagnosis of all forms of leishmaniasis, it is to be pointed out that conventional techniques should not be neglected. In VL, bone-marrow aspirate examination was shown to be sensitive enough, even though not optimal. Examination of cytoconcentrated peripheral blood was demonstrated to be positive in nearly $50 \%$ of VL cases and was proposed to be carried out at first in order to avoid the painful bone-marrow puncture (Ben Said et al., 1998, Chemli et al., 2006). In serodiagnosis, FAT was found to be very efficient and suitable as its sensitivity exceeded $95 \%$ and rK39 DST, even though less sensitive, very useful because it is highly specific, easy to perform and adapted to epidemiological investigations (Saghrouni et al., 2009). PCR is much more adapted to the diagnosis of the asymptomatic and subclinical forms of the disease because of its sensitivity and the scarcity of parasites in such situation. In CL, parasitological diagnosis by demonstrating amastigotes in dermal specimens is again very adequate, even though PCR was demonstrated to be more sensitive (Chargui et al., 2005). In contrast, serodiagnosis is much less useful in CL diagnosis as antibodies' amounts are often very low and results difficult to interpret.

One of the main objectives of this study was to assess whether the activity of our laboratory reflects the actual situation of the leishmaniases at the country level, and whether it could constitute an indicator of public health relevance. As far as VL is considered, most patients originating from Kairouan and Sousse governorates, where are located the most active foci, were investigated for serodiagnosis in our laboratory. So, we may conclude that our findings reflect the actual incidence of VL in the region. This is further confirmed by the comparison of our results to the statistics on the annually recorded cases of VL and edited by the primary health care direction of the Tunisian Ministry of Health (Anonymous). Obviously, our findings match these reports as highest number of registered cases at the national level was in $1992(n=130), 1993(n=122)$ and $2005(n=122)$; and highest number of 
cases diagnosed in our laboratory was as follows: 74 cases in 1992, 72 cases in 1993 and 83 cases in 2005. This is not surprising as nearly $50 \%$ or more of VL cases originate from Kairouan governorate.

Concerning CL, we have to point out that first SCL cases from central Tunisia were diagnosed in our laboratory in patients with clinical presentation found to be evocative of this form, and amastigotes, very suggestive of L. infantum as compared to L. major because of their small size (Ben Saïd et al., 2006). As mentioned in section 2, additional cases were further reported and the spread of SCL towards central and southern Tunisia confirmed. Similarly, the first CCL case originating from outside the original foci of Tataouine area was again diagnosed in our laboratory (Haouas et al., 2005); and CCL spread was further confirmed by additional reports leading to the revised geographical distribution of the disease (Bouratbine et al., 2005; Aoun et al., 2008). In our laboratory, we used to diagnose ZCL since 1986. Up to the late 1990s, the number of diagnosed cases was too moderate as compared to that of ZCL reported cases in the endemic regions (Figures $7 \& 9$ ). This, for at least, the two following reasons: i) at the beginning of the outbreak, many patients suffering from ZCL were only clinically diagnosed, so that only a few of them were addressed to the laboratory for parasitological confirmation, ii) from the 1990s, a great number of families originating from ZCL endemic areas migrated and settled in Sousse city and suburbs, where they progressively constituted a large community. Most of them used to return back to their home of origin for summer holidays where, because continuously exposed to phlebotomine bites, many of them contract leishmaniasis which is later addressed to us for diagnosis. It is worth mentioning that a high proportion of this community originates from Sidi Khelif in Ouled Haffouz delegation, Sidi Bouzid; and and many of them were contaminated there and were later diagnosed in our laboratory. From 2000 and onwards, the number of ZCL patients who attended our laboratory for diagnosis dramatically increased. We consider that since this date the activity of our laboratory indirectly but adequately reflects the actual status of ZCL in central Tunisia, namely in Sidi Bouzid, Mahdia, Kairouan and Sousse governorates. This is best illustrated by our findings in 2004 where $>400 \mathrm{ZCL}$ cases were diagnosed in our laboratory. In the same year, the highest incidence of ZCL (> 15000 cases) was registered at the national level, because of the three epidemic peaks that occurred in Sidi Bouzid (Sidi Bouzid city, Regueb, Menzel Bouzayène), Gafsa (Gafsa city, Sned, Mdhilla) and Kairouan (Nasrallah, Hajeb Layoun, Chrarda) governorates (Anonymous). The peak we registered in 2001 was due to an outbreak that arose in Chahda, a small locality in Chorbène delegation (Mahdia governorate). Indeed, more than $50 \%$ of cases we diagnosed in 2001 were from this locality. A similar peak in Sidi El Heni delegation (Sousse governorate) was registered in 2006, with 107 cases. This peak was followed by a noticeable decrease as soon as control activities were carried out in the area. Similarly the decrease in ZCL incidence shown in our study over the last 5 years can be attributed to an important decrease in the transmission in Sidi Bouzid region where control activities were launched in the mid 2000s (Figure 9). This decrease was reflected on the national level over the same period (Figure 7). Last, our results confirm the seasonal occurrence of ZCL.

Our findings and results show that the activity of our laboratory reflects the situation of leishmaniasis at the regional level and at least in part at the national level, and may be an indicator of public health relevance. It may thus contribute to early alert of health authorities on changing epidemiological trends or emergence of leishmaniasis in the region. However, our activities may not reflect the actual situation and epidemiological changes occurring in farther endemic areas like Gafsa, Tozeur, Kébili, Médenine and Gabès known to include 
highly active foci because very few patients from these regions seek medical facilities in Sousse hospital. Work is in progress to identify and characterize the Leishmania parasites actually circulating in central Tunisia using molecular DNA techniques.

\section{Acknowledgement}

This work received financial support from IAEA (Project ref. TUN/6/012), and from the Ministry of Higher Education and Scientific Research (LR00SP04). We thank the staff of the LEEP, the laboratory of Parasitology of the Faculty of Pharmacy, Monastir and of the laboratory of Parasitology of Farhat Hached hospital, Sousse for their contribution.

\section{References}

Anderson, C. Chronique du kala-azar en Tunisie. Arch. Inst.Pasteur Tunis (1934), 23 : 455-464.

Anderson, C. Chronique du kala-azar.Arch. Inst. Pasteur Tunis (1938), 27 : 96-104.

Anonymous. Epidemiological Bulletins of the Direction of Primary Health care. Ministry of Health, Tunisia, 1980-2010.

Aoun, K., Bouratbine, A., Harrat, Z., Maherzi, A., Belkaid, M., Bousnina S. \& Ben Ismail R. Confirmation of the presence of Leishmania infantum MON-80 in Tunisia. Bul Soc Pathol Exot. (1999), 92 : 29-30.

Aoun, K., Bouratbine, A., Harrat, Z., Guizani, I., Mokni, M., Bel Hadj Ali, S., Ben Osman, A., Belkaïd, M., Dellagi, K. \& Ben Ismail, R. Epidemiologic and parasitologic data concerning sporadic cutaneous leishmaniasis in northern Tunisia. Bull Soc Pathol Exot. (2000), 93: 101-103.

Aoun, K., Bouratbine, A., Harrat, Z., Belkaïd, M. \& Bel Hadj Ali S. Particular profile of the zymodemes of Leishmania infantum causing visceral in Tunisia. Bull Soc Pathol Exot. (2001), $94: 375-377$.

Aoun, K., Chahed, M.K., Mokni, M., Harrat, Z. \& Bouratbine, A. Importance of amastigote forms morphology to differentiate Leishmania infantum and Leishmania major species. Arch Inst Pasteur Tunis (2003), 80 : 53-56.

Aoun. K., Amri. F., Chouihi. E., Haouas, N., Bedoui, K., Benikhelef, R. \& Bouratbine, A. Epidemiology of Leishmania $(L)$ infantum, L. major and L. killicki in Tunisia : results and analysis of the identification of 226 human and canine isolates. Bull Soc Pathol Exot. (2008), 101: 323-328.

Ayadi, A., Ben Ismail, R. \& Ben Rachid, M.S. Spread of Leishmania infantum Kala-azar transmission area towards central and southern Tunisia. Arch Ins Pasteur Tunis (1991), 68 : 269-273.

Bel Hadj, S., Djaiet - Baraket, Z., Jemli, B., Ben Osman, A. \& Chaker, E. Visceral and cutaneous leishmaniasis of the North. Bull Soc Pathol exot, (1996), 89: 269-273.

Bel Hadj, S., Pratlong, F., Mahjoub, H., Toumi, N.H., Azaiez, R., Dedet, J.P. \& Chaker, E. Infantile visceral leishmaniasis from Leishmania infantum Mon-24 : a reality in Tunisia. Bull Soc Pathol Exot. (2000), 93: 12-13.

Bel Hadj, S., Pratlong, F., Toumi, N.H., Kallel, K., Mahjoub, H., Babba, H., Azaiez, R., Dedet, JP. \& Chaker, E. Visceral leishmaniasis in Tunisia: result of the isoenzymatic characterization of 65 Leishmania infantum strains. Trans R Soc Trop Med Hyg. (2002), 96: 627-630. 
Bel Hadj, S., Pratlong, F., Hammami, M., Kallel, K., Dedet, JP. \& Chaker, E. Human cutaneous leishmaniasis due to Leishmania infantum in the Sidi Bourouis focus (Northern Tunisia): epidemiological study and isoenzymatic characterization of the parasites. Acta Trop. (2003), 85: 83-86.

Ben Abda, I., Aoun, K., Ben Alaya, N., Bousslimi, N., Mokni, M. \& Bouratbine, A. Curent epidemiological, clinical and parasitological data concerning cutaneous leishmaniasis in Tunisia. Revue Tunisiennne d'Infectiologie (2009), 2: 31-36.

Ben-Ahmed, K., Aoun, K., Jeddi, F., Ghrab, J., El-Aroui, M.A. \& Bouratbine, A. Visceral leishmaniasis in Tunisia: spatial distribution and association with climatic factors. Am J Trop Med Hyg. (2009), 81: 40-5.

Ben Ammar, R., Ben Ismail, R., Helal, H., Bacha-Hamba, D., Chaouch, A., Bouden, I. \& Ben Rachid, M.S. A new focus of rural cutaneous leishmaniasis in Sidi Saad area (Tunisia). Bull Soc Fr Parasitol. (1984), 2: 9-12.

Ben Hammouda, A., Guizani, I., Jedidi, S., Dellagi, K. \& Ben Ismail, R. Leishmania infantum species-specific kDNA probes: isolation an evaluation. Arch Inst Pasteur Tunis. (2000), 77: 37-43.

Ben Ismail, R., Gradoni, L., Gramiccia, M., Bettini, S., Ben Rachid, M.S. \& Garraoui, A. Epidemic cutaneous leishmaniasis in Tunisia: biochemical characterization of parasites. Trans R Soc Trop Med Hyg, (1986), 80: 669-70.

Ben Ismail, R., Ben Rachid, M.S., Gradoni, L., Gramiccia, M., Helal, H. \& Bach-Hamba, D. Zoonotic cutaneous leishmaniasis in Tunisia: study of the disease reservoir in the Douara area. Ann Soc Belg Med Trop. (1987a), 67: 335-343.

Ben Ismail, R., Gramiccia, M., Gradoni, L., Helal, H. \& Ben Rachid, M.S. Isolation of Leishmania major from Phlebotomus papatasi in Tunisia. Trans $R$ Soc Trop Med Hyg. (1987b), 81: 749.

Ben Ismail, R., Helal, H., Bach-Hamba, D. \& Ben Rachid, M.S. Natural infestation of Phlebotomus papatasi in a focus of zoonotic cutaneous leismaniasis in Tunisia. Bull Soc Pathol Exot. (1987 c), 80: 613-614.

Ben Ismail, R. \& Ben Rachid, M.S. Epidémiologie des leishmanioses en Tunisie, in : Maladies tropicales transmissibles. AUPELF-UREF, Paris, 1989, 73-80.

Ben Ismail, R., Smith, D.F., Ready, P.D., Ayadi, A., Gramiccia, M., Ben Osman, A. \& Ben Rachid, M.S. Sporadic cutaneous leishmaniasis in north Tunisia: identification of the causative agent as Leishmania infantum by the use of a diagnostic deoxyribonucleic acid probe. Trans R Soc Trop Med Hyg. (1992), 86: 508-510.

Ben Rachid, M.S., Hamza, B., Tabbane, C., Gharbi, R., Jeridi, H. \& Ben Saïd, M. Current status of leishmaniasis in Tunisia. Ann Soc Belg Med Trop. (1983), 63: 29-40.

Ben Rachid, M.S., Ben Ismail, R. \& Ben Saïd, M. The ecology of visceral and cutaneous leishmaniasis in Tunisia. In: "Proceedings of the international worshop on leishmaniasis control strategies, 25-29 nov. 1991, Merida, Mexico, IDRC and UPCH editors, (1992, pp. 131-154.

Ben Saïd, M., Amri, F., Mili, A., Ardoin, F., Petithory, J.C. The cytoconcentration in the diagnosis of visceral leishmaniasis in immunocompetent children. Bull Soc Fr Parasitol. (1998), 16: 86-94.

Ben Saïd, M., Guerbouj, S., Saghrouni, F., Fathallah-Mili, A. \& Guizani, I. Occurrence of Leishmania infantum cutaneous leishmaniasis in central Tunisia. Trans $R$ Soc Trop Med Hyg. (2006), 100: 521-526. 
Ben Salah, A., Ben Ismail, R., Amri, F., Chlif, S., Ben Rzig, F., Kharrat, H., Hadhri, H., Hassouna, M., \& Dellagi, K. Investigation of the spread of human visceral leishmaniasis in central Tunisia. Trans R Soc Trop Med Hyg. (2000), 94: 382-386.

Ben Salah, A., Kamarianakis, Y., Chelif, S., Ben Alaya, N. \& Prastacos, P. Zoonotic cutaneous leishmaniasis in central Tunisia : spatio temporal dynamics Int J. Epidemiol. (2007), 36: 991-1000.

Besbès, A., Pousse, H., Ben Saïd, M., Kharrat, H. \& Ghenimi, L. Infantile visceral leishmaniasis in central Tunisia (report of 221 cases). Med Mal Infect. (1994), 24 : 628634.

Bouratbine, A., Aoun, K., Chahed, M.K. \& Ben Ismail, R. Epidemiological data on infantile visceral leishmaniasis in Tunisia. Med Mal Infect. (1998), $28: 446-447$.

Bouratbine, A., Aoun, K., Ghrab, J., Harrat, Z., Ezzedini, M.S. \& Etlijani S. Spread of Leishmania killicki to Central and South-West Tunisia. Parasite (2005) 12: 59-63.

Cardenas, R., Sandoval, C.M., Rodríguez-Morales, A.J., Franco-Paredes, C. Impact of climate variability in the occurrence of leishmaniasis in northeastern Colombia. Am J Trop Med Hyg. (2006), 75: 273-7.

Chadli, A., Ben Rachid, M.S. \& Fhaiel, A. Chroniques des leishmanioses en Tunisie. Arch Inst Pasteur Tunis. (1968), 45: 1-14.

Chaffai, M., Ben Rachid, M.S., Ben Ismail, R., Ben Osman, A. \& Makni, N. Clinicoepidemiological forms of cutaneous leishmaniasis in Tunisia. Ann Dermatol Vénéréol. (1998), 115: 1255-1260.

Chahed, M.K., Hsairi, M., Bousnina, A., Achour, N., Bouratbine, A. \& Hili, K. Assessment of the cutaneous leishmaniasis surveillance system in Tunisia. Revue Tunisienne de la Santé Militaire. (2002), 4: 40-47.

Chargui, N., Bastien, P., Kallel, K., Haouas, N., Akrout Messaadi, F, Masmoudi, A., Zili, J., Chaker, E., Othman, A.D., Azaiez, R., Crobu, L., Mezhoud, H. \& Baba, H. Usefulness of PCR in the diagnosis of cutaneous leishmaniasis in Tunisia. Trans $R$ Soc Trop Med Hyg. (2005), 99: 762-768.

Chargui, N., Haouas, N., Gorcii, M., Akrout Messaadi, F., Zribi, M. \& Baba, H. Increase of canine leishmaniasis in a previously low-endemicity area in Tunisia. Parasite. (2007), 14: 247-251.

Chelbi I, Kaabi B, Béjaoui M, Derbali M, Zhioua E. Spatial correlation between Phlebotomus papatasi Scopoli (Diptera: Psychodidae) and incidence of zoonotic cutaneous leishmaniasis in Tunisia. J Med Entomol. (2009), 46: 400-2.

Chemli, J., Abroug, M., Fathallah, A., Abroug, S., Ben Said, M. \& Harbi, A. Contribution of leucoconcentration in the diagnosis of kala-azar in Tunisia. Med Mal Infect. (2006), 36: 390-392.

Deperet, C. \& Bobinet, E. Du bouton de Gafsa au camp de Sathonay. Archs Med Pharm Milit. (1884), 3: 296-302.

Fichet-Calvet, E., Jommaa, I., Ben Ismail, R. \& Ashford, R.W. Leishmania major infection in the fat sand rat Psammomys obesus in Tunisia: interaction of host and parasite populations. Ann Trop Med Parasitol. (2003), 97: 593-603.

Franke CR, Ziller M, Staubach C, Latif M. Impact of the El Niño/Southern Oscillation on visceral leishmaniasis, Brazil. Emerg Infect Dis. (2002), 8: 914-7. 
Ghrab, J., Rhim, A., Bach-Hamba, D., Chahed, M.K., Aoun, K., Nouira, S. \& Bouratbine, A. Phlebotominae (Diptera: Psychodidae) of human leishmaniasis sites in Tunisia. Parasite. (2006), 13: 23-33.

Gramiccia, M., Ben Ismail, R., Gradoni, L., Ben Rachid, M.S. \& Ben Said, M. A Leishmania infantum enzymatic variant, causative agent of cutaneous leishmaniasis in north Tunisia. Trans R Soc Trop Med Hyg. (1991), 85: 370-371.

Guerbouj, S., Victoir, K., Guizani, I., Seridi, N., Nuwayri-Salti, N., Belkaid, M., Ben Ismail, R., Le Ray, D. \& Dujardin, JC. Gp63 gene polymorphism and population structure of Leishmania donovani complex: influence of the host selection pressure? Parasitology. (2001), 122: 25-35.

Guerbouj, S., Chemkhi, J., Kâabi, B., Rahali, A., Ben Ismail, R. \& Guizani, I. Natural infection of the species Phlebotomus Larroussius langeroni (Diptera: Psychodidae) with Leishmania infantum in Tunisia. Trans $R$ Soc Trop Med Hyg. (2007) 101: 372-377.

Guizani, I., Ben Hamouda, A., van Eys, G.J., Jedidi, S., Dellagi, K. \& Ben Ismail, R. DNA probes development in Tunisia for the identification, the taxonomy and the ecoepidemiology of Old World Leishmania species. Arch Inst Pasteur Tunis. (1993), 70: 363-371.

Guizani, I., Ben Hamouda, A., Jedidi, S., Dellagi, K. \& Ben Ismail, R. Molecular identification of Leishmania: development and application of DNA probes in Tunisia. Arch Inst Pasteur Tunis. (1994a), 71: 439-446.

Guizani, I., van Eys, G.J., Ben Ismail, R. \& Dellagi, K. Use of recombinant DNA probes for species identification of Old World Leishmania isolates. Am J Trop Med Hyg. (1994b), 50: 632-640.

Guizani, I., Dellagi, K. \& Ben Ismail, R. Random amplified polymorphic DNA technique for identification and differentiation of Old World Leishmania species. Am J Trop Med Hyg. (2002) 66: 152-156.

Haouas, N., Chargui, N., Chaker, E., Ben Said, M., Babba, H., Belhadj, S., Kallel, K., Pratlong, F., Dedet, JP., Mezhoud, H. \& Azaiez, R. Anthroponotic cutaneous leishmaniasis in Tunisia: presence of Leishmania killicki outside its original focus of Tataouine. Trans $R$ Soc Trop Med Hyg. (2005), 99: 499-501.

Haouas, N., Gorcii, M., Chargui, N., Aoun, K., Bouratbine, A., Messaadi Akrout F, Masmoudi, A., Zili, J., Ben Said, M., Pratlong, F., Dedet, JP., Mezhoud, H., Azaiez, R. \& Babba, H. Leishmaniasis in central and southern Tunisia: current geographical distribution of zymodemes. Parasite. (2007), 14: 239-246.

Hammoud, M., Ben Hassine, L., Azzabi, S., Ben Abdelghani, K., Kooli, C., Kaouach, Z. \& Khalfallah, N. Adult visceral leishmaniasis: about six cases. Revue Tunisienne de la Santé Militaire. (2004), 6: 54-57.

Hanafi, R., Barhoumi, M., Bel Hadj Ali, S., Guizani, I.. Molecular analysis of Old World Leishmania RAPD markers and development of a PCR assay selective for parasites of the L. donovani species complex. Exp Parasitol. (2001) 98: 90-99.

Harrat, Z., Boubidi, S.C., Pratlong, F., Benikhlef, R., Selt, B., Dedet, JP., Ravel, C. \& Belkaid, M. Description of a dermatropic Leishmania close to L. killicki (Rioux, Lanotte \& Pratlong 1986) in Algeria. Trans R Soc Trop Med Hyg. (2009), 103: 716-720.

Helal, H., Ben Ismail, R., Bach-Hamba, D., Sidhom, M., Bettini, S. \& Ben Rachid, M.S. An epidemiological survey in the focus of zoonotic cutaneous leishmaniaisis 
(Leishmania major) of Sidi Bouzid (Tunisia) in 1985. Bull Soc Pathol Exot. (1987), 80: 349-356.

Kallel, K., Pratlong, F., Belhadj, S., Cherif, F., Hammami, M., Dedet, JP. \& Chaker, E. Cutaneous leishmaniasis in Tunisia: results of the iso-enzymatic characterization of 71 strains. Ann Trop Med Parasitol. (2005), 99: 11-19.

Kallel, K., Ammari, L., Kaouech, E., BelHadj, S., Anane, S., Kilani, B. \& Chaker, E. Asymptomatic beading of Leishmania infantum among Tunisian HIV infected. Pathol Biol. (2007), 55: 521-524.

Kallel, K., Haouas, N., Pratlong, F., Kaouech, E., Bel Hadj, S., Anane, S., Dedet, JP., Babba, H. \& Chaker, E. Cutaneous leishmaniasis caused by Leishmania infantum MON 24 in Tunisia : extension of the focus to the center of the country. Bull Soc Pathol Exot. (2008a), 101: 30-31.

Kallel, K., Pratlong, F., Belhadj, S., Cherif, F., Hammami, H. \& Chaker, E. Isoenzyme variability of Leishmania infantum in Tunisia concerning 245 human strains. Act Trop. (2008b), 106: 132-136.

Khaldi, F., Achouri, E., Gharbi, A., Debabi, A. \& Ben Naceur, B. Infantile visceral leishmaniasis. Data on hospitalized children cases from 1974 to 1988 in INSEE, Tunis. Médecine Tropicale. (1991), 51: 143-147.

Ladjimi, R. \& Lakhoua, M. Premier cas de bouton d'orient dans la banlieue de Tunis. Arch Inst Pasteur Tunis. (1955), 32: 331-336.

Masmoudi, A., Ayadi, N., Boudaya, S., Mziou, T.J., Mseddi, M., Marrakchi, S. \& Ayadi, A. Clinical polymorphism in cutaneous leishmaniasis of center of south Tunisia. Bull Soc Pathol Exot. (2007), 100: 36-40.

Nicolle C. Statistique des trente premières observations tunisiennes de kala-azar. Arch Inst Pasteur Tunis. (1912), 2: 65-67.

Nicolle, C. \& Blanc, G. Extension de la région à bouton d'orient tunisienne. Bull Soc Pathol Exot. (1917), 10: 378-379.

Petithory, J.C., Ardoin, F., Ash, L.R., Vandemeulebroucke, E., Galeazzui, G., Dufour, M., Paugam, A. Microscopic diagnosis of blood parasites following a cytoconcentration technique. Am J Trop Med Hyg. (1997), 57 : 637-642.

Pousse, H., Besbès, A., Ben Said, M., Ghenimi, L. \& Kharrat, H. Epidemiology of human visceral leishmaniasis in Tunisia. J Trop Pediatr. (1995), 41: 191-192.

Rioux, JA., Lanotte, G. \& Pratlong, F. Leishmania killicki n.sp. (Kinetoplastida, Trypanosomatidae), in: Leishmania, taxonomie et phylogenèse, applications écoépidémiologiques. IMEEE, Montpellier, 1986, 139-142.

Saghrouni, F., Gaied-Meksi, S., Fathallah, A., Amri, F., Ach, H., Guizani, I. \& Ben Said, M. Immuno chromatographic rK39 strip test in the serodiagnosis of visceral leishmaniasis in Tunisia. Trans R Soc Trop Med Hyg. (2009), 103: 1273-1278.

Sang, D.K., Njeru, W.K. \& Ashford, R.W. A zoonotic focus of cutaneous leishmaniasis due to Leishmania tropica at Utut, Rift Valley Province, Kenya. Trans $R$ Soc Trop Med Hyg. (1994), 88: 35-37.

Smyth, A.J., Ghosh, A., Hassan, M.Q., Basu, D., De Bruijn, M.H.L., Adhya, S, Mallik, K.K. \& Barker, D.C. Rapid and sensitive detection of Leishmania kinetoplast DNA from spleen and blood samples of kala-azar patients. Parasitology. (1992), 105: 183-192. 
Vermeil, C. Chronique des leishmanioses en Tunisie. Arch Inst Pasteur Tunis. (1956), 33 : 195201.

Zakraoui, H., Ben Salah, A., Ftaiti, A., Marrakchi, H., Zaatour, A., Zaafouri, B., Ahmadi, Z., Garraoui, A., Ben Osman, A. \& Dellagi, K. Spontaneous course of lesions of Leishmania major cutaneous leishmaniasis in Tunisia. Ann Dermatol Venereol. (1995), 122: 405-407.

Zhioua, E., Kaabi, B. \& Chelbi, I. Entomological investigations following the spread of visceral leishmaniasis in Tunisia. J Vector Ecol. (2007), 32: 371-374. 


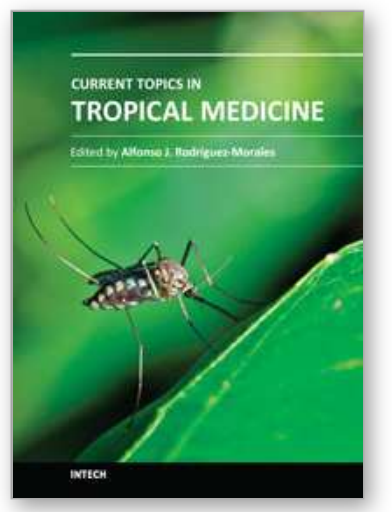

\author{
Current Topics in Tropical Medicine \\ Edited by Dr. Alfonso Rodriguez-Morales
}

ISBN 978-953-51-0274-8

Hard cover, 564 pages

Publisher InTech

Published online 16, March, 2012

Published in print edition March, 2012

Tropical Medicine has emerged and remained as an important discipline for the study of diseases endemic in the tropic, particularly those of infectious etiology. Emergence and reemergence of many tropical pathologies have recently aroused the interest of many fields of the study of tropical medicine, even including new infectious agents. Then evidence-based information in the field and regular updates are necessary. Current Topics in Tropical Medicine presents an updated information on multiple diseases and conditions of interest in the field. It Includes pathologies caused by bacteria, viruses and parasites, protozoans and helminths, as well as tropical non-infectious conditions. Many of them are considering not only epidemiological aspects, but also diagnostic, therapeutical, preventive, social, genetic, bioinformatic and molecular ones. With participation of authors from various countries, many from proper endemic areas, this book has a wide geographical perspective. Finally, all of these characteristics, make an excellent update on many aspects of tropical medicine in the world.

\title{
How to reference
}

In order to correctly reference this scholarly work, feel free to copy and paste the following:

Akila Fathallah Mili, Fatma Saghrouni, Zeineb BenSaid, Yusr Saadi- BenAoun, Ikram Guizani and Moncef BenSaid (2012). Retrospective Analysis of Leishmaniasis in Central Tunisia: An Update on Emerging Epidemiological Trends, Current Topics in Tropical Medicine, Dr. Alfonso Rodriguez-Morales (Ed.), ISBN: 978953-51-0274-8, InTech, Available from: http://www.intechopen.com/books/current-topics-in-tropicalmedicine/retrospective-analysis-of-leishmaniasis-in-central-tunisia-an-update-on-emerging-epidemiological-tre

\section{INTECH}

open science | open minds

\section{InTech Europe}

University Campus STeP Ri

Slavka Krautzeka 83/A

51000 Rijeka, Croatia

Phone: +385 (51) 770447

Fax: +385 (51) 686166

www.intechopen.com

\section{InTech China}

Unit 405, Office Block, Hotel Equatorial Shanghai

No.65, Yan An Road (West), Shanghai, 200040, China 中国上海市延安西路65号上海国际贵都大饭店办公楼 405 单元

Phone: +86-21-62489820

Fax: $+86-21-62489821$ 
(C) 2012 The Author(s). Licensee IntechOpen. This is an open access article distributed under the terms of the Creative Commons Attribution 3.0 License, which permits unrestricted use, distribution, and reproduction in any medium, provided the original work is properly cited. 